\title{
A POBREZA TURÍSTICA NO MERCADO DE PACIFICAÇÃO: reflexões a partir da experiência da Favela Santa Marta
}

\author{
Bianca Freire-Medeiros* \\ Márcio Grijó Vilarouca** \\ Palloma Menezes***
}

\begin{abstract}
Desde os anos 1990, a Rocinha veio se consolidando como paradigma de favela turística, valendo-se de um modelo centrado na atuação das empresas privadas externas à favela e na indiferença permissiva do poder público. Este artigo analisa as inflexões práticas e discursivas que permitiram a quebra desse paradigma e a emergência de um modelo baseado tanto em parcerias entre poder público e mercado, quanto na mobilização de moradores como empreendedores. A partir de trabalho de campo e entrevistas, examinam-se as percepções e justificações desses vários atores - poder público, operadoras de turismo, moradores - envolvidos na conversão do Santa Marta em atração turística. A hipótese defendida é que o Santa Marta, primeira favela a receber uma Unidade de Polícia Pacificadora, oferece um ponto privilegiado de observação do novo campo de forças que define o lugar a ser ocupado pelas favelas em um projeto que toma o Rio de Janeiro como cidade-cartão-postal.
\end{abstract}

Palavras-chave: Turismo. Favela. Rio de Janeiro. Pobreza. Pacificação.

\section{INTRODUÇÃO}

Há pelo menos duas décadas, uma vasta literatura no campo das ciências sociais tem insistido que estamos diante de um processo crescente de integração dos sistemas econômico, social e cultural (King, 1991; Robertson, 1992; Sasken, 1998). Independentemente do batismo que se dê a esse processo - globalização, mundialização, transnacionalização -, o turismo pode ser tomado, a um só tempo, como causa e efeito dele. O turismo é um dos fluxos através dos quais trocas econômicas, sociais e culturais acontecem, e o crescente escopo dessas trocas, por sua vez, torna-se um estímulo ao turismo (Richards, 2007; Urry,

\footnotetext{
* Universidade de São Paulo (USP). Faculdade de Filosofia Letras e Ciências Humanas (FFLCH). Departamento de Sociologia. Programa de Pós-Graduação em Sociologia.

Av. Prof. Luciano Gualberto, 315. Cidade Universitária. Cep: 05508-010. Butantã - São Paulo - Brasil. freiremed@ hotmail.com

** Fundação Getulio Vargas. Centro de Pesquisa e Documentação de História Contemporânea do Brasil.

Praia de Botafogo, 190, 14o andar. Cep: 22253-900. Rio de Janeiro - Rio de Janeiro - Brasil. marcio.grijo@fgv.br

${ }^{* \star \star}$ Fundação Getulio Vargas. Centro de Pesquisa e Documentação de História Contemporânea do Brasil.

Praia de Botafogo, 190, 140 andar. Cep: 22253-900. Rio de Janeiro - Rio de Janeiro - Brasil. pallomamenezes@gmail.com
}

2007). Localidades as mais diversas buscam, então, redescobrir sua "vocação" e redefinir sua "identidade" - atributos variados que, a partir de operações de city branding, entre outras, sejam capazes de bem posicioná-las na nova competitividade territorial cuja lógica de projeção passa, sobretudo, pelo desenvolvimento de uma economia simbólica da cidade (Zukin, 1995).

O turismo, visto como engenho que permite forjar uma nova imagem urbana, passa a encontrar cenário em localidades antes tidas como "não turísticas". Embalados em novas premissas históricas, culturais e estéticas, territórios marginais - slums, favelas, townships - adquirem usos e sentidos inesperados. Abrese, no processo, a possibilidade de produzir, promover e consumir uma mercadoria intangível, isto é, baseada na experiência, a que um de nós chamou, em oportunidades prévias, de pobreza turística (Freire-Medeiros, 2009, 2013). Transformada em commodity com um valor monetário acordado entre promotores (operadoras de turismo, ONGs, moradores engajados no mercado turístico) e consumidores (turistas de várias partes do mundo, especialmente 
aqueles oriundos do chamado rico norte), a experiência da pobreza é comercializada em localidades associadas à segregação, desordem, insalubridade e violência. Há de se atentar, portanto, para o caráter sociogeográfico que singulariza esse produto: slums, townships e favela tours ${ }^{1}$ prometem um mergulho "[...] em territórios que habitam a imaginação internacional como uma metonímia e uma metáfora para subdesenvolvimento e iniquidade" (Freire-Medeiros, 2015, p. 189).

A pobreza turística, no Brasil, encontra seu referente simbólico em uma favela imaginária, necessariamente fincada na montanha, entre a mata e o mar, de onde se podem avistar os bairros mais ricos da cidade. No que se refere à oferta e à demanda comerciais, esse território da imaginação passa a fazer parte do pacote turístico que confere especificidade à cidade do Rio de Janeiro, em geral complementando outros itinerários mais tradicionais ou mesmo competindo com eles. Seu referente material inconteste, entre início dos anos 1990 até pelo menos fins dos anos 2000, foi a Rocinha, conhecida no mercado turístico como "a maior favela da América Latina”. Este artigo examina o momento que marca o fim dessa hegemonia e o início de um capítulo inédito na biografia da favela turística.

Se a Rocinha, ao longo de duas décadas, representou a vitória de um modelo fundado tanto no protagonismo das empresas privadas externas à favela quanto no silêncio (ou mesmo oposição) do poder público, nossa hipótese é que, no contexto da chamada política de pacificação (Silva, 2010; Cunha; Mello, 2011; Burgos et al., 2012; Cano; Borges; Ribeiro, 2012; Barbosa, 2012; Carvalho, 2012; Ost; Fleury, 2013; Leite, 2014; Menezes, 2015), pôde ser estabelecido um novo campo de forças que permitiu a gestação e a consolidação de um modelo cujo sustento se encontra tanto nas parcerias entre poder público e mercado, quanto no agenciamento de moradores conver-

${ }^{1}$ Para um panorama comparativo entre essas três modalidades de excursões pagas, ver Freire-Medeiros 2013. tidos em empreendedores turísticos. Este artigo se propõe a oferecer um retrato detalhado desse processo de emergência da "outra" favela turística, partindo de reflexões acumuladas por cada um dos autores em suas pesquisas (Freire-Medeiros, 2013; Menezes, 2015), bem como de um projeto de investigação comum, intitulado "Turismo em favelas pacificadas", realizado sob encomenda do Ministério do Turismo (MTur) em 2011². Nossa intenção aqui é, mais especificamente, examinar as percepções e justificações, nos termos de Boltanski e Thévenot (1999), dos principais atores diretamente envolvidos nos primeiros momentos da conversão do Santa Marta em atração turística oficial da cidade do Rio de Janeiro.

O Santa Marta localiza-se em uma encosta íngreme, na divisa entre os bairros de Botafogo e Laranjeiras, na prestigiosa Zona Sul. A favela, segundo dados da Secretaria de Estado de Segurança (Seseg), tem uma área de 54.692 $\mathrm{m}^{2}$, onde vivem cerca de seis mil moradores. O território está delimitado do lado direito por um plano inclinado, inaugurado em maio de 2008, com cinco estações, e do lado esquerdo por um grande muro de concreto que, batizado de "ecobarreira", foi construído em 2009 pelo Governo do Estado para conter a expansão da favela em direção à mata tropical.

O trânsito de visitantes pelo Santa Marta não constitui exatamente uma novidade: a favela, ao longo de sua história, atraiu constantemente o olhar curioso de anônimos e celebridades. No fim da década de 1980, porém, essa curiosi${ }^{2}$ Este artigo beneficia-se das pesquisas realizadas desde 2005 por Freire-Medeiros sobre turismo em áreas de pobreza, cuja síntese mais recente encontra-se no livro Touring Poverty (2013); da etnografia de longa duração realizada por Palloma Menezes entre 2011 e 2014, nas favelas Santa Marta e Cidade de Deus, e do material produzido pela equipe coordenada por Freire-Medeiros e Grijó Vilarouca, no contexto do projeto de pesquisa "Turismo em comunidades pacificadas", financiado pelo MTur e pela Fundação Getúlio Vargas. Desenvolvido entre os meses de março e junho de 2011, o projeto realizou 40 entrevistas em profundidade com diversos atores envolvidos nas atividades turísticas ou por elas afetados diretamente (moradores, guias locais, comerciantes, agências de turismo e staff da UPP) e dois surveys, um com turistas estrangeiros (400 questionários) e o outro com turistas nacionais e estrangeiros no aeroporto internacional do Rio de Janeiro (amostra de 900 entrevistados). Para outros desdobramentos desse projeto, ver Freire-Medeiros e colaboradores (2012, 2013) e Freire-Medeiros e Vilarouca (2015). 
dade não encontraria motivação na vista privilegiada para o Cristo Redentor, o Pão de Açúcar e outras paisagens consagradas no repertório turístico, mas na espetacularização midiática das "guerras" ocorridas no morro. ${ }^{3}$ Posteriormente, reforçaram-se ainda mais as imagens negativas da favela, a partir, sobretudo, de três produtos de ampla circulação: em 1996, do videoclipe de Michael Jackson e das polêmicas em torno de sua gravação no morro; em 1999, do documentário "Notícias de uma Guerra Particular" - produzido por João Moreira Salles e Kátia Lund - que retratava o cotidiano compartilhado por traficantes, policiais e moradores; e, em 2003, do livro $O$ Abusado, de Caco Barcellos, que virou best-seller ao contar as desventuras do "ex-dono do Santa Marta”, o traficante Marcinho VP. ${ }^{4}$ Nesse período, as visitas eram esporádicas e intermediadas por representantes de instituições locais - como o Grupo $\mathrm{Eco}^{5}$ e a Associação de Moradores -, sem que se estabelecesse um mercado turístico propriamente dito.

Não se pode negar, portanto, que foi a inauguração, em dezembro de 2008, da primeira Unidade de Polícia Pacificadora da cidade do Rio de Janeiro a grande responsável pelos novos fluxos de circulação pelo morro. Em um curto espaço de tempo, foi se tornando corriqueira a presença de jornalistas brasileiros e estrangeiros, estudantes de universidades de diversos países e pesquisadores de diferentes áreas, que chegavam à favela na tentativa de compreender o processo de "pacificação". Enquanto isso, o Santa Marta passava a receber um enorme número de empresários, empreendedores, representantes do poder público, celebridades e, sem dúvida, turistas, muitos turistas.

${ }^{3}$ Inúmeras matérias foram divulgadas sobre a disputa travada entre os traficantes Zaca e Cabeludo pelo controle da venda de drogas: "Em outubro de 1987, a guerra entre os dois levou pânico aos moradores da favela e de Botafogo. Para surpreender os rivais, os traficantes atiravam nos transformadores, deixando a favela às escuras. Foram 14 dias de tiroteios diários e de mortes" (Zacarias..., 2001).

${ }^{4}$ Ainda em 2003, Marcinho VP foi assassinado no presídio Bangu 3 por outros integrantes do Comando Vermelho que o acusaram de ter "falado demais". O corpo do traficante foi encontrado dentro de uma lata de lixo coberto por livros.

${ }^{5}$ O Grupo Eco, entidade sem fins lucrativos de caráter educacional e cultural, atua na favela desde 1976.
Para o bem e para o mal, o Santa Marta tornou-se um "laboratório" no qual tem sido testada uma série de intervenções e iniciativas tanto públicas como privadas (Ost; Fleury, 2013; Menezes, 2015). Serviços diversos foram regularizados - energia elétrica, água, televisão a cabo - e 70 dos $97^{6}$ estabelecimentos comerciais existentes em 2011 haviam sido legalizados. Um dos principais argumentos utilizados pelos agentes da Prefeitura para incentivar os comerciantes a legalizar seus estabelecimentos foi justamente sinalizar que um "projeto de turismo" seria lançado na favela e que o consequente aumento do fluxo de turistas no morro poderia gerar um aumento nas vendas - desde que o comércio local estivesse devidamente regularizado. O projeto foi inaugurado em 2010 e batizado de "Rio Top Tour: o Rio de Janeiro sob um novo ponto de vista". ${ }^{7}$ É dele que trata a próxima seção, ou seja, do pacote que os agentes públicos idealizaram para embalar o produto Santa Marta e entregá-lo ao mercado turístico. Em seguida, ouvimos as agências privadas e seus guias, assim como os guias-moradores que, naquele momento, foram os principais responsáveis por estabelecer um mercado turístico na favela, buscando identificar e compreender as categorias por eles acionadas no exercício de legitimação do "produto Santa Marta", diante, sobretudo, dos questionamentos críticos dos moradores. Abordamos, ainda, os desdobramentos recentes das disputas entre esses diversos atores, com foco na proposição, por parte dos moradores e guias locais, de outras embalagens para o produto Santa Marta.

${ }^{6}$ A presidente da Associação de Comerciantes nos informou que o número de estabelecimentos comerciais cresceu muito após a chegada da UPP, e hoje há cerca de 150 estabelecimentos.

${ }^{7} \mathrm{O}$ projeto foi idealizado pela jornalista e mestre em antropologia Mônica Rodrigues. Em 14 de julho de 2011, Mônica postou, em seu blog pessoal, as premissas do Rio Top Tour: "Consiste em uma abordagem que valorize a cultura e produza uma autoestima no morador da favela, ou comunidade, como queiram [...]. É um manifesto pela integração, pela mistura entre experiências do asfalto e morro sendo que depois da chegada do projeto, os moradores têm que estar prontos a discutir o que querem de igual para igual. Sem vítimas nem vencedores. Nem o turismo explora o favelado nem o favelado explora o gringo, falando dentro da linguagem que o preconceito gosta de usar". (Rodrigues, 2011). 
É importante lembrar que há uma pluralidade de modos de justificação mutuamente incompatíveis sendo acionados pelos atores sociais não apenas nas favelas cariocas, mas no vasto campo do turismo de pobreza mundo afora (ver a coletânea editada por Franzel et al. e o número especial do periódico Tourism Geographies, ambos de 2012). Neste artigo, as incompatibilidades presentes no chão empírico e cotidiano do Santa Marta turístico não são entendidas como simples contradições ou inconsistências, mas como disputas acerca das regras de justificação aceitas (Boltanski; Thévenot, 1999). Não trabalhamos, portanto, com as críticas externas ao campo do turismo de pobreza, mas com os acordos e desacordos, altercações e controvérsias gerados dentro do próprio campo por aqueles que foram responsáveis pelos primeiros momentos da conversão do Santa Marta em atração turística no contexto da chamada UPP.

Diversas pesquisas acadêmicas, até 2012, davam conta dos impactos positivos gestados no âmbito daquela "nova” política de segurança pública, que inicialmente logrou êxito na redução das recorrentes e violentas incursões policiais e, consequentemente, dos tiroteios, das mortes violentas, da presença ostensiva de armas e do domínio dos traficantes ○ - ou seja, dos principais elementos em torno : dos quais a representação da violência urba\ na estava fundada (IBPS, 2009; CECIP, 2010; Souza e Silva, 2010; Burgos et al., 2011; Cano, 2012). Muitos moradores de favela onde havia UPPs, por sua vez, diziam perceber a redução da arbitrariedade e da violência policial, bem ¿. como a ampliação de sua "liberdade de ir e ¿ vir", fatos que estariam relacionados ao “[...] iे maior controle social, interno e externo, sobre

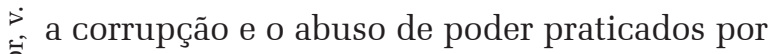
policiais" (Musumeci et al., 2013, p. 1). (Ver também Oliveira; Abramovay, 2012; Rodrigues; Siqueira, 2012; Serrano-Berthet, 2013). A bem da verdade, a contabilização da queda no número de "autos de resistência" (Misse et al., 2013) parecia indicar que, de certo modo, a UPP poderia ajudar a "civilizar" a ação policial ou que ela poderia se tornar uma "política de proteção da população contra a própria polícia” (Misse, 2014, p. 682). Outros estudos documentavam uma drástica redução dos homicídios, dos roubos e da violência armada em geral, não só no interior das favelas, mas também no seu entorno (Cano, Borges, Ribeiro, 2012; Zaluar, 2014), ampliando o grau de consenso em torno da política. No entanto, segundo a cronologia apontada por Menezes (2015), a partir de 2011, iniciou-se um rearmamento da crítica às UPPs, com lastro no questionamento da frágil provisão de serviços públicos nas favelas, na identificação de um processo de gentrificação ou de "remoção branca", do aumento de crimes não letais e, por fim, do incremento da corrupção policial, assim como da desconfiança e apreensão com o processo de reacomodação com o tráfico ${ }^{8}$.

Porém se muito já foi afirmado, em um hiato de tempo relativamente curto, sobre as UPPs como "prática interessada", para usarmos a expressão de Foucault, ainda falta compreender o papel que dispositivos apresentados como politicamente neutros e tecnicamente legitimados, como é o caso do turismo, cumprem de fato. É com esse desafio em mente que tomamos os experimentos, disputas e justificações em torno do Santa Marta turístico como exemplo do que estamos chamando aqui de prática cotidiana de sustentação de um projeto mais amplo, voltado para as favelas que compõem a cidade-cartão-postal e que se vale da política de segurança construída em torno da UPPs e de seus braços sociais, mas que não se limita a eles.

${ }^{8}$ No momento em que escrevemos este artigo, as denún-
cias de corrupção e abuso policial têm crescido, assim
como a postura dos grupos armados que controlam a ven-
da de drogas nas favelas tem se tornado mais destemida,
indicando que os traficantes estão cada vez mais descren-
tes no poder efetivo dessa nova forma de policiamento.
Há, assim, uma progressiva redução na aposta de que as
UPPs seguirão sendo a solução para o problema da violên-
cia urbana no Rio de Janeiro. 


\section{SANTA MARTA NA EMBALAGEM OFICIAL: "O Rio de Janeiro sob um outro ponto de vista"}

Rio de Janeiro, 30 de agosto de 2010. Uma grande festa na quadra da Escola de Samba do Santa Marta recepciona o prefeito Eduardo Paes, a primeira-dama do Governo do Estado, Adriana Anselmo, o então presidente da República, Luiz Inácio Lula da Silva, vários ministros e o presidente da Associação de Moradores do Santa Marta, Zé Mário Hilário. Estão todos ali reunidos para o lançamento do projeto Rio Top Tour. Em discurso durante a cerimônia, Paes fez uma pequena digressão histórica, marcando uma nítida fronteira entre supostos "antes" e "depois":

[...] aqui do lado [bairro de Laranjeiras] fica o Palácio da Cidade. Há cerca de oito anos atrás o prefeito da cidade do Rio de Janeiro, independente de quem era - era o Conde - teve que, para poder trabalhar com tranquilidade, botar um vidro blindado no gabinete dele. [...] Esse momento que a gente tem aqui, do presidente da República estar vindo aqui olhar o lançamento de um programa turístico nessa comunidade, vale mais para todos os cariocas do que qualquer obra de não sei quantos bilhões que a cidade pudesse estar recebendo do presidente da República hoje. [...] O que se conseguiu foi trazer aquilo que era mais fundamental para as pessoas da cidade do Rio de Janeiro, que foi paz. [...] Hoje o prefeito da cidade do Rio de Janeiro não precisa mais de vidro blindado. [...] Qualquer cidadão vem aqui e qualquer turista vem aqui. Não é que virou o paraíso, aqui tem os mesmos problemas que tem ali embaixo, que tem ali na esquina e é assim que o Rio de Janeiro quer ser. Uma cidade pacificada, tranquilizada, e que as pessoas possam caminhar por ela com toda liberdade. [...] Essa é uma vitória, uma conquista desse Programa que se lança aqui hoje e acima de tudo dessa celebração. Todo mundo pode vir, que as portas estão abertas no Dona Marta e em toda a cidade (Prefeito Eduardo Paes, 30 ago. 2010).

As palavras de Eduardo Paes indicavam que a "pacificação" do Santa Marta e a inauguração do projeto Rio Top Tour pretendiam a ruptura com um passado de confinamento que marcara a cidade como um todo, e a conquista da mobilidade dos cidadãos - e dos turistas, é claro - por áreas antes vedadas até mesmo ao poder público. O mandatário justificava a criação e a inauguração do projeto de turismo na primeira favela "pacificada", associando o Rio Top Tour, portanto, não só a uma tentativa de estimular a economia local, mas também a uma conquista mais ampla do "direito de ir e vir". A mesma ênfase na mobilidade como direito foi, em seguida, reforçada pela Secretária Estadual de Turismo, Esporte e Lazer, Márcia Lins:

\footnotetext{
Há mais de um ano a gente vem tratando na Secretaria de Turismo desse programa [...]. Exatamente o que nosso prefeito acabou de falar, que é a celebração do direito de ir e vir. Nós estamos inaugurando no Santa Marta, que é a primeira comunidade pacificada, vamos estender para outras comunidades pacificadas. [...] Então eu queria em nome do nosso governador - que a gente não pode falar, ${ }^{9}$ mas vou falar - agradecer ao governo federal por essa importante parceria. Até 2014 a gente vai estar oferecendo para a Copa do Mundo uma cidade totalmente pacificada, uma cidade de portas abertas e que pode ser visitada, sim, por todos. Pelos seus moradores, por todo o Brasil e pelos moradores do mundo inteiro que visitam o Rio de Janeiro (Secretária Estadual de Turismo, Esporte e Lazer, Márcia Lins, 30 ago. 2010).
}

As falas dos representantes oficiais aqui recuperadas deixam claro que o lançamento do Rio Top Tour estava associado à tentativa de divulgar, nacional e internacionalmente, as mudanças estruturais que vinham ocorrendo na cidade que, àquela data, já tinha sido escolhida como uma das sedes da Copa do Mundo FIFA 2014 e lançado sua candidatura como sede dos Jogos Olímpicos de 2016. Um dos principais desafios a superar, para que fosse possível sediar esses e outros megaeventos previstos, era o problema da segurança pública, e o projeto Rio Top Tour representava, sem dúvida, uma oportunidade estratégica para promover e vender a nova imagem do Rio. Não surpreende, assim, que o projeto tenha apresentado a chamada "favela modelo" como uma imagem-síntese da

9 Sérgio Cabral não pôde participar da cerimônia e seu nome não poderia ser citado porque a inauguração do projeto coincidiu com o período de campanha eleitoral e, naquele momento, ele era candidato à reeleição. 
nova cidade que seria oferecida: uma cidade em que moradores e visitantes podem circular livremente e, não menos importante, com oportunidades de negócios para todos que estejam dispostos a nela "empreender".

Tampouco causa surpresa que o projeto Rio Top Tour tenha contado não apenas com a parceria entre os três níveis de governo, mas também com apoio do SEBRAE-RJ e de outros representantes do setor privado (a fábrica de tintas Coral, por exemplo). Para os moradores que desejavam adotar o turismo como uma fonte de renda, foi aberta pela Investe Rio, agência de fomento do Governo do Estado, uma linha de crédito que ia de $\mathrm{R} \$ 300,00$ a $\mathrm{R} \$$ 6 mil por negócio. A orientação para os moradores interessados foi fornecida pelo SEBRAE em oficinas de empreendedorismo realizadas na própria favela e esteve diretamente vinculada à regularização do comércio local.

O convênio firmado entre a Secretária Estadual de Turismo e o MTur permitiu que fossem mapeados os atrativos turísticos e distribuídas placas de sinalização bilíngue em pontos estratégicos do morro. Foram instalados, ainda, um grande mapa da favela e um estande com informações turísticas na Praça Corumbá, na divisa com o asfalto, onde potenciais turistas passaram a receber orientações - de estagiários do curso de turismo do Colégio S亏 Estadual Antônio Prado Junior e de moradores \் que então cursavam a oficina de monitores de turismo local (não se tratava ainda de curso de guiamento), também conduzida pelo SEBRAE.

Mas nem só de palco vivem as políticas públicas, como bem nos lembra Ervin Goffman. A fala abaixo é exemplar do quão ne- cessárias foram as tessituras de bastidores na construção da "Pacificação" que, como qualquer macropolítica, depende não apenas de formas institucionalizadas e estruturais de justificação, mas igualmente de agenciamentos e mediações informais:

Veio a Secretaria [de Turismo] com o projeto Rio Top Tour. A gente [a operadora de turismo e a SETUR] foi lá, montou aquele mapa doido, disse como é que tinha que ser, onde tinham que entrar as placas. Enfim, tentamos formatar uma coisa que desse certo e que deu [...]. A ideia é Disney! O cara [turista] tem que ficar lá dentro. Ele sobe, desce, vem, tem mais uma coisa, uma atração, tem uma capoeira, sei lá, inventa. A gente ainda encontra alguns problemas, óbvio, [...] mas já está muito melhor do que quando a gente começou. A inserção do governo federal, a laje do Michael Jackson, não sei o que da Alicia Keys, enfim, [com] toda essa coisa que vai aparecendo, vai se compondo um produto maior (Sóciodiretor de empresa de turismo).

Ao recordar o processo de instauração do Rio Top Tour, nosso entrevistado evidencia o uso estratégico do turismo como prática cotidiana - e supostamente desinteressada - de sustentação do projeto mais amplo de Pacificação. Valer-se de lógicas e técnicas aparentemente apolíticas não significa, obviamente, estar blindado contra reflexões críticas e questionamentos variados por parte de atores cujos princípios de legitimação baseiam-se em outras premissas:

Esse projeto Rio Top Tour - Santa Marta é o chamado projeto paraquedas. O projeto, como já aconteceu em outras ocasiões, é elaborado geralmente em gabinetes com ar refrigerado, com cafezinho, é meio assim 'toma!' Então, eu acho que qualquer projeto deve ser debatido, discutido (Homem, liderança, morador do Santa Marta).

Ainda que o caráter pouco democrático do Rio Top Tour tenha gerado insatisfações, o fato é que, a partir de sua implementação, a rotina de todos os envolvidos seria irreversivelmente alterada: os promotores de turismo das operadoras privadas, que antes atuavam em outras favelas, tiveram de se adaptar à realidade do Santa Marta; alguns moradores tiveram de calçar os sapatos de guias e empreendedores turísticos; outro tanto se viu ocupando o papel, no mais das vezes, pouco confortável, de atração turística. Embora o senso comum e a mídia, via de regra, percebam de maneira indiscriminada o "tour em favela", durante o trabalho de campo vimos repetir-se, pouco a pouco, aquilo que já sabíamos ser a realidade empírica da Rocinha: o surgimento de inúme- 
ras formas de conceber e comercializar o produto favela convivendo e disputando entre si. Dependendo do guia, o tour pelo Santa Marta pode, por exemplo, começar pela parte de baixo da favela ou pelo Pico (parte alta do morro); a subida ou a descida do morro pode ser feita a pé ou de bondinho; incluir ou não almoço em um restaurante local; pode ser diurno ou incluir um pernoite no morro; contar ou não com visitas a instituições locais como a Associação de Moradores e o Grupo Eco; incluir ou não atividades especiais, como oficinas de capoeira, de samba ou de confecção de pipa, etc. É das práticas situadas de críticas efetivas e justificações aceitáveis, das negociações e renegociações cotidianas entre os atores envolvidos nessas várias modalidades de turismo que circunscreveram a primeira fase de construção do Santa Marta como destino turístico que trata a próxima seção.

\section{MUITAS EMBALAGENS PARA UM MESMO PRODUTO OU VÁRIOS PRO- DUTOS NA MESMA EMBALAGEM? Negociações entre a favela imagina- da, vendida, fotografada e vivida}

A transformação do Santa Marta em um ponto turístico deu-se a partir não só da elaboração e do lançamento do projeto Rio Top Tour, mas também de esforços menos visíveis empreendidos pelos que ali passaram a atuar e que, no processo, ajudaram a estabelecer, na favela, fluxos de visitação regulares. São exemplos desses esforços os investimentos relacionados: a) à adaptação de antigas e formação de novas agências de turismo e de guias independentes, incluindo-se parcerias e arranjos entre guias-moradores e operadoras externas; b) ao incremento de um comércio local voltado para os turistas (bares e restaurantes, barraquinhas de artesanato e lojas de suvenires); c) ao desenvolvimento de estratégias de formatação, divulgação e comercialização do produto "favela pacificada".
Em suas narrativas sobre esses vários investimentos, os atores apareciam, naquele momento, polarizados basicamente entre os "de fora" e os "de dentro" do morro. O primeiro polo incluía as agências de turismo e os guias independentes que não tinham a base de suas atividades comerciais no Santa Marta. Esses agentes, em sua maioria, atuavam na Rocinha e, a partir de 2010, deslocaram a totalidade ou parte de suas atividades para a primeira favela "pacificada". No polo oposto, encontravam-se alguns poucos moradores que, há anos, levavam turistas para visitar a favela e que intensificaram sua atuação como guias após a chegada da UPP, além de vários outros sem qualquer experiência anterior, mas que começaram a se profissionalizar e a atuar no trade com o lançamento do Rio Top Tour.

Os "de dentro" não eram um grupo homogêneo, assim como os "de fora" nem sempre eram reconhecidos ou se reconheciam como compartilhando princípios e formas de agir comuns. No entanto, os "de dentro", em muitos momentos, organizavam-se como grupo orientado por um conjunto de valores definidos, no mais das vezes, em oposição aos "de fora", vistos como um "outro" sem relação identitária com a favela e, por conseguinte, sem compromisso com sua história e seu desenvolvimento. Como afirmou um guia-morador durante evento público realizado no Santa Marta:

Eles vêm, contam um monte de mentira, vêm com o jipe lá por trás, com um guia que não é da comunidade, [que] não sabe a história da comunidade. Contam um monte de mentiras... A empresa não contrata os monitores locais. [O motorista] deixa eles [turistas] lá em cima, eles depois descem, dão a volta com o guia dentro da comunidade; desrespeitam a privacidade dos moradores; fotografam as pessoas sem pedir permissão; falam um monte de mentira; não podem ver uma criança que falam que aquela criança está passando fome, que está pedindo esmola. Falam coisas absurdas! ${ }^{10}$

Os "de dentro" questionavam a legitimida-

${ }^{10}$ Depoimento de um guia-morador durante o $16^{\circ}$ Fórum da UPP Social. 
de das narrativas dos agentes externos que operavam o acesso e a intermediação à favela. Hifenizados então como moradores-guias, passaram a reclamar para si o direito de embalar e comercializar a história do Santa Marta. O monopólio dessa narrativa memorial, verdadeira porque vivida, garantiria um "produto favela" diferenciado:

\begin{abstract}
Pessoas que são de fora do morro, que não moram aqui, não conhecem nada da nossa realidade. Eu acho errado essas pessoas estarem guiando turistas porque elas não conhecem nossa realidade. Eu acho que esse turismo tem que ser feito por nós, moradores, e que a gente possa escolher o que é que a gente quer mostrar, o que é que tem que ser mostrado. (Estudante, guia-morador do Santa Marta).
\end{abstract}

Por seu lado, o dono de uma das agências privadas severamente criticada pelos "de dentro" defendia-se, na entrevista que nos foi concedida em maio de 2011, dizendo que "até gostaria” de contratar moradores como guias, mas que eles não tinham qualificação suficiente. Segundo sua lógica de justificação, naquele momento, o principal impedimento para incorporar os moradores como mão de obra assentava-se em um fator objetivo: os guiasmoradores não tinham fluência em outros idiomas, inviabilizando o trabalho com uma clientela até então totalmente composta por estrangeiros. ${ }^{11}$

Outra contenda girava em torno da relação entre turismo e comércio local. Enquanto os "de dentro" incluíam bares, restaurantes e lojinhas em seus roteiros, supostamente incentivando o desenvolvimento econômico da favela, nos tours realizados pelos "de fora", os turistas "simplesmente passavam" sem nada consumir. Os guias "de fora" assumiam que raramente paravam nos estabelecimentos comerciais da favela, mas deslocavam a responsabilidade dessa decisão para os próprios turistas que, segundo eles, tinham nojo e desconfiança das condições de higiene dos produtos oferecidos:

${ }^{11}$ Ao longo dos anos, o número de turistas brasileiros aumentou consideravelmente no Santa Marta. Ainda que não haja estatísticas oficiais, a percepção dos guias que atuam na favela é de que o público se diversificou e, atualmente, inclui até alguns cariocas.
Cartão postal, por exemplo, foi o que eu vi os turistas comprando. Comer, eu não dou espaço para comer nada no tour. Não paro para comer, paro em algum lugar para beber e é uma parada rápida, de cinco minutos. [...]. Tem gente que vai querer saber da higiene, como é que é, que bebida está ali, [mesmo] bebida em lata ou engarrafada. (Guia de turismo independente).

Para além da dimensão econômica, porém, o produto "favela pacificada" englobava a disputa em torno de outro aspecto constitutivo fundamental: as representações construídas e difundidas da favela e de seus moradores. A oposição entre os "de fora" e os "de dentro" tornava-se evidente quando os atores avaliavam a forma como o produto favela era, no seu entender, vendido pelos outros e quando se sentiam impelidos a justificar o modo como eles próprios o formatavam e comercializavam cotidianamente. Uma série de convergências e desacordos nada óbvios surgia, por exemplo, quando perguntávamos a nossos interlocutores sobre as especificidades do Santa Marta como produto turístico e lhes pedíamos que elencassem os principais pontos fortes e fracos da favela. Se praticamente todos citavam a Laje e a estátua do Michael Jackson como os grandes destaques, alguns guias-moradores questionavam o fato de o local não ser mais lembrado como "Laje do ambulatório do Dedé". A mudança do nome representaria um descaso com a história de lutas da favela, já que Dedé foi um antigo morador que em muito contribuiu para a melhoria da prestação de serviços no Santa Marta, não sendo menos importante na trajetória da favela do que o pop star. Como resumiu uma guia de turismo nascida na localidade: "Matou a história. Sério, porque o cara que quer entreter só pensa no dinheiro: 'Next, próximo, próxima atração'. [...] Eu não acho que a gente está aqui para isso" (guia-moradora).

Os "de dentro" defendiam, portanto, que a memória de lutas do Santa Marta fosse lembrada e celebrada. Seus enunciados de justificação apelavam para a importância das histórias locais, de suas próprias experiências 
de vida na favela e das características peculiares do morro que só os 'nascidos e criados' ali poderiam conhecer. Os guias "de fora", por sua vez, não estavam de fato preocupados em contar aos turistas uma história específica do Santa Marta, mas visavam, outrossim, a tornar aquela experiência generalizável, como explicou um de nossos interlocutores:

O importante para o turista, na minha opinião, é ele saber como é que o morro funciona. Não especificamente aquele, ele está visitando um, mas na verdade, aquele um representa o todo. Eu não me concentro muito no Santa Marta, eu me concentro em como funciona, desde quanto tempo tem favela, quantos habitantes moram no Rio de Janeiro em favela, quem são eles, o que fazem. [...] Digamos que metade [do tour] dá uma generalizada sobre favela e a outra metade é sobre o que está trazendo de positivo a UPP. (Guia de turismo independente).

De uma maneira geral, os operadores de turismo avaliam os atributos operacionais de cada favela com intuito de verificar sua viabilidade comercial - tamanho, perfil dos moradores, atrativos, acessibilidade, dentre outros fatores. Isso não quer dizer, porém, que deixasse de prevalecer a busca pelo produto genérico:

[Favela tour] era uma coisa que a gente sempre vendeu. Ainda mais depois que a gente começou a ter outras oportunidades, não vendeu mais o nome, vendeu um produto. Não é vender 'favela da Rocinha', é vender 'favela'. Porque aí se tem liberdade de ir para qualquer favela. (Sócio-diretor de uma empresa de turismo).

Se, no plano do discurso, é possível eleger a favela genérica como produto, na prática não há como ignorar as especificidades dos territórios empíricos. Vejamos o que nos diz o mesmo entrevistado ao refletir sobre as diferenças entre o Santa Marta e a Rocinha, onde atuara por mais de uma década:

Tirar da Rocinha e jogar para o Santa Marta é uma diferença muito grande. Até em tamanho, em tempo de roteiro, o que fazer [...] A Rocinha você anda toda de carro, o Santa Marta você anda todo a pé. Então, as particularidades foram diferentes. A gente não tem aquilo que a Rocinha tinha, que era o centro de artesanato, aquela coisa toda... No Santa Marta, você não tem realmente nada, parece o Projac, tudo limpo, não tem fio, não tem "gato". Isso era legal na Rocinha, os gatos, enfim, essa falta do poder público é o grande atrativo. No Santa Marta, você perdeu um pouco esse encanto, mas continua sendo uma favela com outros encantos. (Sócio-diretor de empresa de turismo).

Por consequência e de maneira contraintuitiva, o trabalho dos guias, no contexto da "pacificação", tornava-se, assim, bem mais desafiador:

Sobe por Laranjeiras, chega lá em cima tem o mirante [...]. Passa na UPP, desce [a favela] toda a pé e o jipe pega eles lá embaixo. [...] Se o guia for um bom guia, ele prende o cara lá o tempo que ele quiser. Se o guia for um mau guia, o tour dura dez minutos. Depende do quanto de tempo ele fala... É o guia que faz esse timing: conta, mostra, fotografa, brinca, ri, para mais tempo na laje. (Sócio-diretor de empresa de turismo).

Embora não discordassem que a competência do guia é fundamental, os "de dentro" apontavam que seu trabalho poderia ser facilitado se houvesse mais eventos, festas e atividades culturais na favela. Esses atrativos ajudariam a "fixar" os turistas no morro e até fazer com que consumissem mais, gerando renda para o comércio local. Aqui, a "crítica corretiva”, para usarmos a expressão de Boltanski e Chiapello (1999), continuava a ter como alvo os agentes externos, mas já não se voltava para as operadoras de turismo. A força de seu argumento é dirigida aos patrocinadores, que não apoiavam como eles gostariam a promoção de eventos no morro, e, principalmente, ao comando da UPP. Como resumiu um morador-guia:

A UPP bloqueia isso, bloqueia aquilo, tudo é caso de polícia e não é caso de cultura. Acabou, vai ter aquele passeio chato: dá a volta e vai embora. Porque o funk não é valorizado; aí começa a vir: jazz para o morro, a "galera não sei o que" para o morro, violino para o morro; e a cultura do morro que é o samba, que é o funk, que é o forró, não sei o quê, só martelado... (Guia-morador). 
Enquanto os "de dentro" associavam a falta de atrativos à carência de investimentos públicos e privados, alguns "de fora" pareciam operar na lógica contrária. Como é destacado nos trechos citados acima, para o dono de uma agência de turismo externa, o Santa Marta teria perdido "um pouco do encanto" justamente por conta dos investimentos feitos pelo poder público e a partir dos quais os signos associados à pobreza e à desordem, como a grande quantidade de lixo espalhado e os fios emaranhados, tornaram-se menos visíveis.

Mesmo que os dejetos, as valas abertas e outros marcadores pudessem parecer menos ou mais discretos, dependendo do lugar de fala, fato é que o foco das câmeras dos turistas continuava a se voltar justamente para esses signos capazes de conferir à experiência da pobreza (Freire-Medeiros, 2013) sua materialidade, vez que operam como representações da condição de morar em favelas, como marcações limítrofes das diferenças entre o turista e o favelado. Os moradores com quem conversamos se diziam extremamente desconfortáveis com a produção desse tipo de fotografia, cuja circulação ajudaria a reproduzir estigmas seculares:

O que preocupa é o que eles levam daqui de imagem. De argumento lá pra fora: 'Subi na Santa Marta, só encontrei...' o quê? Então essa interrogação é que me preocupa. Hoje eu acho que eles levam a imagem muito negativa do lixo da comunidade. (Liderança, morador do Santa Marta).

Todo dia tem gente nesse morro. Eles querem tirar foto até do cocô do cachorro que tem no chão! Acho impressionante! Falei: 'Será que lá não tem cachorro?' Não sei, eu queria entender. Outro dia eu perguntei para o guia, ele ficou rindo. Eu falei: 'Você não pode perguntar para mim por que ele tira foto do cocô, porque eu não entendo, gente!' Eu falei: 'Eu acho que eles querem realmente mostrar a pobreza da comunidade. Não leva nada de bom, porque só vêm para cá para mostrar o que é feio'. (Moradora do Santa Marta).

As fotografias produzidas durante os passeios geravam tanta polêmica, que incluímos, em nossos roteiros de entrevista, uma pergunta específica sobre o tema. Invasão, intromissão, exposição, falta de respeito, falta de privacidade, ausência de liberdade foram algumas das referências evocadas pelos moradores para descrever a situação:

O que eles têm que entender é o seguinte: aqui não
tem nenhuma celebridade! Outro dia, o turista tirou
foto e algumas pessoas não gostaram, foram lá e pro-
testaram: 'Não tira foto de mim, eu não gosto'. Aí os
turistas apagaram. Eles tiraram foto, assim, como se
fosse um objeto qualquer. E não é um objeto qualquer,
é um ser humano, uma pessoa com todo o respeito!
(Prestador de serviços, morador do Santa Marta).

Parte significativa dos moradores com quem conversamos, ao longo da pesquisa, afirmou que não se incomodava em ser fotografada por turistas, desde que - fato destacado por todos - a autorização fosse pedida antes. Havia, contudo, uma desconfiança particular em relação às fotos de crianças: muitos expressavam medo de que um turista fosse pedófilo ou que pudesse postar a foto de crianças da favela em sites pornográficos. Algumas vezes, a indignação escalou para confrontos abertos:

Outro dia eu estava descendo e o gringo estava tirando foto da criancinha brincando sem a mãe. Ele ficou tirando foto dela, e eu voltei e disse que não podia, e taquei a máquina dele na água! [...] Eu falei que não podia e ele sabia que não podia! E ele fez assim mesmo. Somos nós que somos os animais? Somos nós que somos os não civilizados? [...] Fico apavorada quando eu vejo aquelas velhas, loiríssimas, branquíssimas, que apontam para você como se você fizesse parte do cenário. Eu não me conformo com isso! (Liderança, moradora do Santa Marta).

Os "de fora" reconhecem que a privacidade é, de fato, uma questão especialmente preocupante, que precisa ser estudada para "minimizar impactos". Muitos moradores reclamam que não podem mais deixar a porta e janelas de suas casas abertas - o que é um costume local, já que as casas são muito próximas uma das outras e há pouca ventilação nos becos mais apertados. Havia os que, reconhecendo estar na "rota turística", passaram a deixar "a casa mais arrumada”. Um dos entrevistados expressou a confusão de sentimentos vivenciada por grande parte dos moradores com quem conversamos: 
Agora a gente está se acostumando [...] Está se adaptando a isso, porque antes, como não tinha, a gente ficava mais à vontade. Hoje a gente sente a presença de outras pessoas, então a gente fica... Não sei se acuado, mas a gente fica... Como é essa sensação de receber? É diferente, é diferente, porque a gente não está acostumado. A gente tem que se adaptar. (Estudante, morador do Santa Marta).

Na visão da maioria, os culpados pelo comportamento pouco respeitoso dos turistas eram as agências e os guias, a quem caberia orientar melhor os visitantes. Todos os guias "de dentro" e "de fora" - assumiram que lhes cabia alertar seus clientes em relação à fotografia, para evitar pelejas entre eles e os moradores, até porque, se deixassem, os "turistas fotografam qualquer coisa, até o interior das casas". Nesse contexto, todos os guias procuravam se defender da analogia feita não apenas por moradores, mas igualmente pela mídia e o senso comum, entre "turismo na favela" e "zoológico de pobre". A tensão entre a "condição de humanidade" evocada pelos moradores da favela e a percepção dos turistas de que a favela estaria aquém de preceitos jurídicos, inclusive do direito à privacidade, seria constitutiva do próprio produto:

É normal, você está dentro de um local que tem muita gente, você não vai conseguir agradar todo mundo. Nunca. É só tentar achar uma forma de não incomodar. E a forma que a gente tem é educando o turista dentro do carro para ele ser o menos agressivo possível. Não tirar foto de criança, não invadir o espaço do cara, não abrir a porta da casa. Mesmo que ela esteja escancarada, não fotografar lá dentro. Mantenha a educação! É simples, não precisa ser muito [...] (Sócio-diretor de empresa de turismo).

Pouco antes de encerrar nosso trabalho de campo, placas indicativas, que apontavam onde era proibido fotografar, foram distribuídas pelo morro - uma resposta do Poder Público às inúmeras reclamações de moradores. Àquele tempo, já havia, no Santa Marta, uma quantidade expressiva de negócios que orbitavam em torno da favela turística, desde agências de turismo (Brazilidade, Favela Tour San- ta Marta, Favela Santa Marta Turismo, TouRio New Paths in Rio e Favela Scene), passando por estabelecimentos de hospedagem até uma marca de produtos voltados especialmente para turistas que evoca em seu nome - Santa Marta We Care -, a já mencionada passagem de Michael Jackson pela favela nos anos 1990.

Dois anos depois da implantação da UPP, raros eram os dias em que não havia algum turista circulando pelo Santa Marta, câmera fotográfica em punho, indício claro do sucesso do produto "favela pacificada". Todavia é interessante notar que, na percepção dos atores envolvidos, o Santa Marta, para se constituir como atração turística, seguia dependendo dos mesmos atributos básicos que definem a favela turística desde sua origem nos anos 1990: pobreza, risco e exotismo. A fala a seguir é exemplar:

Eu acho que as pessoas estão romantizando a miséria da gente, a pobreza da gente... A nossa violência, a pobreza, os negros, o pobre, o latino, é tudo exótico para eles. Aí imagina poder dizer que você pisou naquele local que se vê na televisão! É como se você fosse um Indiana Jones! [...] deve ser muito diferente para eles realmente. Então eu acho que as pessoas vêm querendo dar uma de Indiana Jones. E a miséria virou cult para alguns. E eu acho que é chique hoje em dia poder dizer que você conhece uma favela; e que você já até subiu em uma favela! 'Olha que legal'! (Funcionária pública, moradora do Santa Marta).

Obviamente isso não significa dizer que nada mudou. A chegada da UPP impôs novas regras de conduta no morro e a necessidade de negociação entre novos atores, que passaram a se mover de acordo com uma complexa lógica que um de nós chamou de "lógica de campo minado" (Menezes, 2015). Durante a pesquisa, ouvimos recorrentemente que, antes da "pacificação", qualquer um que se aventurasse a visitar o Santa Marta seguia um "código de ética” silencioso, porém encarnado de maneira eloquente nos traficantes ostensivamente armados que controlavam o território da favela. Esse controle imposto pelos bandidos implicava que raramente havia pessoas circulando desacompanhados de algum contato que co- 
nhecesse minimamente o morro, assim como eram raras as fotografias tiradas sem um pedido prévio de autorização. Tais práticas, como são narradas aqui, tornaram-se corriqueiras depois da chegada da UPP.

A tensão, antes velada, entre os "de dentro" e os "de fora" tornou-se evidente com a criação, em 2010, do Comitê de Turismo do Santa Marta. Idealizado por Sheila Souza - uma das poucas moradoras com formação em turismo e que já trabalhava na área mesmo antes do Rio Top Tour -, o Comitê passou a reunir residentes não apenas do Santa Marta, mas de outras favelas que tiveram o primeiro contato com turismo a partir dos cursos oferecidos pelo projeto Rio Top Tour. Embora existissem e ainda existam muitas divergências e disputas internas ao grupo, foi possível, a partir da construção do consenso em torno de alguns pontos julgados essenciais, criar estratégias que acabaram por constranger as empresas externas a fazer parcerias com os guias locais. Os moradores narram que "a batalha foi longa" - durou mais de três anos -, porém vitoriosa. Em 2013, um guia-morador resumiu com empolgação:

Derrotamos o inimigo! A gente fez um vídeo dos moradores falando o que achavam da [nome da empresa] e outro de uma reunião do Comitê. [...] Mostramos os vídeos. Ele abaixou a cabeça [...] Aí a gente conseguiu uma parceria com eles. Quinze reais por pessoa. Hoje em dia, eles não vendem mais o Favela Tour no Santa Marta. Só vendem se [algum cliente] disser: 'Olha só, tenho 100 pessoas que querem o Santa Marta, você me leva?' Aí eles fazem. Mas se falar favela eles levam para a Rocinha. Isso foi por conta da nossa pressão. Agora ele vem aí de vez em quando com guia local e paga os R\$15 [...]. Melhor até que nem venha! As outras agências, a maioria tem parceria. Se não [fizer parceria] alguém que fala inglês vai falar para o turista que isso não está certo, que ele está pagando para vir, mas a comunidade não vai ser beneficiada. Causa constrangimento para a própria empresa. Eu liguei para uma empresa e falei isso tudo. Depois a empresa me ligou querendo parceria, querendo contato, aí levei tudo para o Comitê. Não quis só para mim. Tem um telefone do Comitê, que agora está ficando com uma dos guias locais e tem uma sequência [de atendimento aos clientes]. (Trecho de entrevista com um guia-morador).
Nos últimos anos, o Comitê estabeleceuse, portanto, como um importante espaço de debate entre os "de dentro" e os "de fora". E, a partir desses debates e negociações, cresceram as parcerias entre agências externas e guias locais. Mas, se alguns agentes locais se diziam satisfeitos com as parcerias, outros membros do Comitê estavam menos otimistas. Um guiamorador, por exemplo, argumentava que algumas agências querem apenas "auferir lucro com a miséria”; por isso, sugeria que os moradores trabalhassem de forma independente e organizassem o que ele chama de "turismo de reivindicação" ou "turismo social":

Eu sugiro fazer um turismo de reivindicação que seja divulgado nas redes sociais. Galera que está lá vai me ouvir aí nos rincões mais distantes do planeta. Visitem o Santa Marta, conversem com lideranças legítimas, que não querem auferir lucro com a miséria. Mas aí eu sugiro, na minha opinião, o turismo social. Não assistencialista. Eu distingo muito bem o assistencial do social. Assistencial: 'ah, tadinho, coitadinho, miserável’. Não! Queremos investimento social. (Liderança, guia-morador).

\section{CONSIDERAÇÕES FINAIS}

Ao recuperar os primeiros momentos de conversão da favela Santa Marta em atração turística, voltamo-nos para os padrões de conduta e argumentação levados a cabo pelos atores sociais envolvidos, privilegiando a análise de suas respectivas justificações, evocadas nos conflitos entre os "de dentro" e os "de fora". O foco, no chão empírico do Santa Marta, contudo, não responderia a demandas de teorização mais amplas se abstraíssemos as relações entre esse "caso particular do possível" e a complexidade da assim chamada cidade neoliberal ou, para usarmos um termo ainda mais apropriado ao Rio de Janeiro dos megaeventos, da cidade-cartão-postal. Afinal, como sugere com precisão Vera Telles (2015, p. 19), é na falta de comunicação entre a abstração teórica e as dinâmicas urbanas apreendidas etnograficamente que reside o que a autora chama de "ponto 
cego dos estudos urbanos", onde se camuflam ou se tornam invisíveis "[...] os modos pelos quais processos socioespaciais da chamada cidade-mercado se territorializam em contextos situados [...]". Não foi outra nossa intenção ao enfocar essa prática de sustentação cotidiana das lógicas e circuitos de mercado, com suas formas de controle e gestão dos espaços e das populações, que é o turismo.

Ainda que, no debate acerca do turismo em áreas de pobreza, muito do esforço de reflexão se volte para as disputas em torno da dimensão econômica, nossa pesquisa permitiu perceber que a crescente presença de turistas fez com que agenda extravasasse a questão redistributiva, relativa à repartição dos ganhos econômicos gerados com o turismo no Santa Marta. Ficou evidente, por exemplo, que, entre os moradores comuns (aqueles sem envolvimento direto com a atividade turística), não havia consenso nem em relação ao produto favela turística per se, nem às várias 'embalagens' que se encontravam então disponíveis. As opiniões eram diversas e as demandas, muitas vezes, contraditórias. A única convergência dava-se justamente em torno do repúdio aos instantâneos fotográficos que congelam como suvenires os dejetos de animais, o lixo, a precariedade, e que, pior de tudo, transformam os moradores em meros aspectos do cenário, com a respectiva negação do direito à privacidade. As justificações dos agentes promotores do turismo, "de dentro" ou "de fora", como demonstramos aqui, precisaram dialogar com essas "críticas corretivas" e com elas lidar na prática cotidiana.

Mesmo que a criação da "embalagem oficial" para o produto "favela turística pacificada" tenha se dado em um momento de consenso positivo em torno das UPPs, não foi possível evitar que moradores criticassem a política pública de segurança responsável pelo incremento das atividades turísticas no morro. A percepção de que tanto a UPP quanto o projeto Rio Top Tour respondiam a stakeholders externos (aos bairros do entorno e aos turistas que viriam para os grandes eventos) em detrimento dos mora- dores da favela foi tomando o lugar do otimismo inicial. Quando encerramos nosso trabalho de campo, ambos os projetos eram vistos como compartilhando de uma espécie de vício de origem comum, que poderia minar - e de fato o fez em alguma medida - sua legitimidade.

Recebido para publicação em 01 de outubro de 2015 Aceito em 22 de fevereiro de 2016

\section{REFERÊNCIAS}

BARBOSA, A. R. Considerações introdutórias sobre territorialidade e mercado na conformação das Unidades de Polícia Pacificadora no Rio de Janeiro. Revista Brasileira de Segurança Pública, São Paulo, v. 6, p. 256-265, ago./ set. 2012 .

BOLTANSKI, L.; THÉVENOT, L. The sociology of critical capacity. European Journal of Social Theory, v. 2, n. 3, p. 359-377, 1999.

BURGOS, M. et al. O efeito UPP na percepção dos moradores das favelas. Desigualdade e diversidade, Rio de Janeiro, v. 11, p. 49-97, ago./dez. 2012.

CANO, I.; BORGES, D.; RIBEIRO, E. Os donos do morro: uma análise exploratória do impacto das Unidades de Polícia Pacificadora no Rio de Janeiro. São Paulo: Fórum Brasileiro de Segurança Pública, 2012.

CARVALHO, M. A experiência da pacificação em um conjunto de favelas na Tijuca: rupturas e contradições na gestão da ordem pública. Comunicações do ISER, [S.n.], v. 67, p. 172-183, 2012

CENTRO DE CRIAÇÃO DE IMAGEM POPULAR (CECIP). $O$ impacto sobre a primeira infância das políticas de segurança pública e iniciativas comunitárias em comunidades urbanas de baixa renda. Rio de Janeiro, 2010.

CUNHA, N.; MELLO, M. Novos conflitos na cidade: a UPP e o processo de urbanização na favela. Dilemas: revista de estudos de conflito e controle social, Rio de Janeiro, v. 4, n. 3, p. 371-401, jul./set. 2012..

FREIRE-MEDEIROS, B. Gringo na laje: produção, circulação e consumo da favela turística. Rio de Janeiro: FGV Editora, 2009

2013. Touring Poverty. Londres: Nova York: Routledge.

Governamentalidade e mobilização da pobreza urbana no Brasil e na África do Sul: favelas e townships como atrações turísticas. In: BIRMAN, P. et al. (Org.). Dispositivos urbanos e trama dos viventes: ordens e resistências. Rio de Janeiro: FGV Editora: Faperj, 2015.

FREIRE-MEDEIROS, B. VILAROUCA, M. G ; MENEZES P. Gringos no Santa Marta: quem são, o que pensam e como avaliam a experiência turística na favela. In: SANTOS; A. M. S. P.; MARAFON, G. J.; SANT'ANNA (Org.). Rio de Janeiro: um território em mutação. Rio de Janeiro: Gramma, 2012

FUNDAÇÃO GETULIO VARGAS. Avaliação do impacto do policiamento comunitário na Cidade de Deus e no Dona Marta. Rio de Janeiro: Fundação Getulio Vargas, 2009. Mimeografado.

INSTITUTO BRASILEIRO DE PESQUISA SOCIAL (IBPS). 
O impacto das unidades de polícia pacificadora nas favelas da cidade do Rio de Janeiro. Relatório de pesquisa. Rio de Janeiro, 2009.

KING, A. Culture, globalization and the world system. London: Macmillan, 1991.

LEITE, M. P. Entre a 'guerra' e a 'paz': unidades de polícia pacificadora e gestão dos territórios de favela no Rio de Janeiro. Dilemas: revista de estudos de conflito e controle social, v. 7, p. 625-642, out./dez. 2014

MACHADO DA SILVA, L. A. Afinal, qual é a das UPPs. Rio de Janeiro: [S.n.], 2010. Disponível em: www. observatoriodasmetropoles.ufrj.br. Acesso em: data mar. 2010 .

Violência urbana, segurança pública e favelas: o caso do Rio de Janeiro atual. Caderno CRH, Salvador, v. 23, p. 283-300, maio/ago. 2010.

MENEZES, P. ‘Favela Modelo': a study on housing, belonging and civic engagement in a 'pacified' favela in Rio de Janeiro, Brazil. In; KLAUFUS, C.; OUWENEEL, A. (Ed.). Housing and belonging in Latin America. New York: Berghahn Books. 2015.

Os rumores da "pacificação": a chegada da UPP e as mudanças nos problemas públicos no Santa Marta e na Cidade de Deus. Dilemas: revista de estudos de conflito e controle social, v. 7, p. 665-683, out./dez. 2014.

Entre o "fogo cruzado" e o "campo minado": uma etnografia do processo de "pacificação" de favelas cariocas. 2015. $45 \mathrm{f}$. Tese (doutorado) - Instituto de Estudos Sociais e Políticos, Universidade do Estado do Rio de Janeiro, Rio de Janeiro, 2015.

MISSE, D. Cinco anos de UPP: Um breve balanço. Dilemas: revista de estudos de conflito e controle social,,v. 7 , n. 3 , p. 675-700, 2014.

MISSE, M. et al. Quando a polícia mata: homicídios por "autos de resistência" no Rio de Janeiro (2001-2011). Rio de Janeiro: Booklink, 2013.

MUSUMECI, L. et al. Ser policial de UPP: aproximações e resistências. Boletim Segurança e Cidadania, v. 14, p. 1-28, 2013.
OLIVEIRA, F; ABRAMOVAY, P. As UPPs e o longo caminho para a cidadania nas favelas do Rio de Janeiro. In: OLIVEIRA, F. L. et al. UPPs, direitos e justiça: um estudo de caso das favelas do Vidigal e do Cantagalo. Rio de Janeiro: FGV, 2012. p. 123-47.

OST, S.; FLEURY, S. O mercado sobe o morro: a cidadania desce? Efeitos socioeconômicos da pacificação no Santa Marta. Dados, v. 56, 2013, p. 635-671.

RODRGUES, M. O método: como fazer o Rio top tour na favela? Disponível em: http://turismodapaz.blogspot.com. br. Acesso em: 2 set. de 2015.

RODRIGUES, A.; SIQUEIRA, R.; LISSOVSKY, M. Unidades de polícia pacificadora: debates e reflexões. Comunicações do ISER, ano 31, n. 67, p. 9-51, 2012.

SERRANO-BERTHET, R. (Coord.). O retorno do Estado às favelas do Rio de Janeiro: uma análise da transformacão do dia a dia das comunidades após o processo de pacificação das UPPs. Rio de Janeiro: FGV: Banco Mundial, 2013.

SOUZA E SILVA, J. As unidades de polícia pacificadora e os novos desafios para as favelas cariocas. In: SEMINÁRIO ASPECTOS HUMANOS DA FAVELA CARIOCA.2010, Rio de Janeiro. Anais... Rio de Janeiro: Laboratório de Etnografia Metropolitana, 2010.

TELLES, V. Cidade: producão de espaços, formas de controle e conflitos. Revista de Ciências sociais, Fortaleza, v. 46 , n. 1, p. 15-41, jan./jun. 2015.

URRY, J. Mobilities. Cambridge: Polity, 1990.

ZACARIAS travou "guerra" por controle do tráfico em morro do Rio. Folha de São Paulo, São Paulo, 10 jan. 2001. Disponível em: http://www1.folha.uol.com.br/folha/ cotidiano/ult95u18957.shtml. Acesso em: 7 mar. 2013.

ZALUAR, A. Dilemas, desafios e problemas da UPP no Rio de Janeiro. XII Annual Internacional Conference of the Brazilian Studies Association (BRASA). London, 2014.

ZUKIN, S. The Cultures of Cities. Cambridge MA: Blackwell, 1995. 


\section{SLUM TOURISM IN THE PACIFICATION MARKET: reflections based on the experience of Favela Santa Marta}

\author{
Bianca Freire-Medeiros \\ Márcio Grijó Vilarouca \\ Palloma Menezes
}

\author{
Bianca Freire-Medeiros \\ Márcio Grijó Vilarouca \\ Palloma Menezes
}

LE TOURISME DE LA PAUVRETÉ AU SEIN DU MARCHÉ DE PACIFICATION: réflexions issues de l'expérience dans la Favela Santa Marta
Since the 1990's, Rocinha has been securing itself as a paradigm of touristic favela based on a model centered in the action of private companies outside the favela and in the indifference of the government. This article analyzes the practical and the discursive inflections which permitted the end of this paradigm and the emergence of a model based on public and private partnerships as well as in the organization of the local residents as entrepreneurs. Through field research and interviews, the perceptions and the justifications of these agents involved in the transformation of Santa Marta in a tourist attraction (the public sphere, tourism agencies, local residents) were examined. The hypothesis advocated here is that the Santa Marta, the first favela with a Pacifying Police Unit, offers a privileged point to observe the new power networks that defines the place to be occupied by the favelas in a project which makes Rio de Janeiro a postcard city.

Keywords: Tourism. Favela. Rio de Janeiro. Poverty. Pacification.
Depuis les années 1990, la “Rocinha” s'est consolidée comme un paradigme de favela touristique. Elle est présentée comme un modèle centré sur l'action d'entreprises privées n'appartenant pas à la favela et sur l'indifférence permissive des pouvoirs publics. Cet article analyse les inflexions pratiques et discursives qui ont permis de rompre avec ce paradigme et de permettre l'apparition d'un modèle basé autant sur un partenariat des pouvoirs publics et des marchés que sur la mobilisation des habitants en tant qu'entrepreneurs. Grâce à un travail sur le terrain et à des interviews, il a été possible d'analyser les perceptions et les justifications de ces différents acteurs - pouvoirs publics, voyagistes, habitants - impliqués dans la conversion de Santa Marta en attraction touristique. L'hypothèse avancée est que Santa Marta est la première favela qui a été dotée d'une Police Pacificatrice, qu'elle offre un point de vue privilégié pour l'observation de nouvelles forces qui définissent l'endroit destiné à l'occupation de favelas comme un projet qui donne à Rio sa caractéristique de carte postale.

Mots-CLÉs: Tourisme. Favela. Rio de Janeiro. Pauvreté. Pacification.

Bianca Freire-Medeiros - Doutora em Historia e Teoria da Arte e da Arquitetura - Binghamton University. Professora do Departamento e do Programa de Pós-Graduação em Sociologia da Universidade de São Paulo. Coordenadora do UrbanData-Brasil: Banco de dados bibliográfico sobre o Brasil urbano. Entre suas publicações mais recentes está o livro livro Touring Poverty. London: Routledge (Advances in Sociology series), 2013; 2015).

Márcio Grijó Vilarouca - Doutor em Ciência Política pelo IUPERJ (atual IESP). Professor da Escola de Ciências Sociais da Fundação Getulio Vargas (FGV/RJ) e Coordenador do Setor de Pesquisa do CPDOC. Integra o Núcleo de Pesquisa FGV-Opinião, desenvolvendo pesquisas na área de métodos quantitativos e qualitativos. Seus mais recentes artigos, em parceria com Freire-Medeiros, e relacionados ao tema favela e turismo, são: International tourists in a "pacified" favela: profiles and attitudes. The case of Santa Marta (2013); Would You Be a Favela Tourist? Confronting Expectations and Moral Concerns amongst Brazilian and Foreign Potential Tourists (2015).

Palloma Menezes - Pós-doutoranda do Centro de Pesquisa e Documentação de História Contemporânea do Brasil da Fundação Getulio Vargas (CPDOC/FGV). Pesquisadora do Coletivo de Estudos sobre Violência e Sociabilidade (CEVIS/UERJ) e integrante do Projeto Temático FAPESP, "A gestão do conflito na produção da cidade contemporânea: a experiência paulista”. Trabalha com temas relacionados à sociologia e antropologia urbana, favelas e periferias, violência urbana, crime, segurança e políticas públicas. 
